\title{
Accidents related to manure in eastern Switzerland: an epidemiological study
}

\author{
A Knoblauch, B Steiner, S Bachmann, G Trachsler, R Burgheer, J Osterwalder
}

\begin{abstract}
Objectives-Liquid manure systems and manure pits are major hazards in the agricultural workplace. The incidence of accidents related to manure is unknown. The objective of this study was to survey the liquid manure facilities of farms in eastern Switzerland and find the incidence of accidents related to manure in the region.

Methods-Retrospective cohort study and cross sectional survey of 210 farms in eastern Switzerland.

Results-The incidence of accidents related to manure was found to be $10 \cdot 4 / 1000$ person-years. Most accidents were categorised as minor-that is, had a benign outcome for the people involved or involved animals only. One in 33 of the farms surveyed was the scene of an accident related to manure each year.

Conclusions-The medical literature on accidents related to manure mostly reports accidents with catastrophic outcomes. This study shows that this type of accident is only the tip of the iceberg. Most of the accidents reported in this study belong to a category that has hitherto been un-noticed and unreported. The term "accident related to manure" covers a broad range of events, and those resulting in serious human illness or death represent only a small part of this spectrum. A wide variety of liquid manure systems were found on the farms surveyed. Very few liquid manure facilities conformed to published safety standards.
\end{abstract}

Division of Pulmonary

Medicine, Medical

Department A,

Cantonal Hospital,

St Gall, Switzerland

A Knoblauch

$S$ Bachmann

Advisory Board for

Accident Prevention in

Agriculture,

Schöftland,

Switzerland

B Steiner

$S$ Bachmann

R Burgheer

Central Emergency

Department, Cantona

Hospital, St Gall,

Switzerland

J Osterwalder

Correspondence to:

Dr A Knoblauch, Leitender

Arzt, Pneumologische

Abteilung, Medizin A

Kantonsspital, 9007 St Gall,

Switzerland.

Accepted 1 April 1996

Keywords: liquid manure; accidents; incidence

There is a high incidence of occupational accidents on farms in Switzerland. In 1991 there were 237 workplace accidents per 1000 insured person-years in agricultural operations, second only to the building industry (313 accidents per 1000 insured personyears). ${ }^{1}$ However, with figures of 135 for women and 140 for men (1990-4) agriculture had the highest accident related standardised mortality ratio of any sector (Thomas Spuler, Bundesamt für Statistik, Schwarztorstrasse 96, CH-3003 Bern, personal communication). In 1986 in the United States there were 0.52 deaths related to work in agriculture per 1000 man-years - more than in any other sector, including the mining industry. ${ }^{2}$

The hazards are quickly apparent to anyone who looks closely at a farm. Those to be found on Swiss farms include, in decreasing order of importance, lack of railings or other safety features in agricultural buildings, which may result in falls, the presence of heavy animals that can inflict severe injuries on humans, all kinds of machinery, especially tractors, timber cutting operations, and all manner of hand tools. Finally, farms harbour noxious gases, liquids, and chemicals that are all potentially hazardous. Liquid manure is a particularly important member of this group, as it presents several dangers: people risk falls into open or inadequately secured storage tanks; uncontrolled fermentation produces several toxic gases, including hydrogen sulphide, which, when inhaled in high concentrations, rapidly produces unconsciousness; and fermentation also produces methane, a highly flammable gas that can cause fires and explosions.

Although the scientific literature contains a constant stream of reports on individual cases, there is a notable lack of epidemiological data on accidents related to manure. This study, the product of collaboration between doctors of the Division of Pulmonary Medicine, Kantonsspital St Gallen (St Gall cantonal hospital) with a special interest in occupational medicine and accident prevention experts of the Swiss Advisory Board for Accident Prevention in Agriculture (Beratungsstelle für Unfallverhütung in der Landwirtschaft) ${ }^{\star}$, was undertaken with the aim of determining the incidence of such accidents at livestock raising farms in Switzerland and conducting a survey of liquid manure facilities. The ultimate goal is to provide information that will contribute to accident prevention on farms.

\section{Methods}

STUDY DESIGN AND SAMPLING PROCEDURE

To find the frequency of accidents related to manure we conducted a retrospective cohort study combined with a cross sectional survey to gather demographic data and descriptive

«The Advisory Board for Accident Prevention in Agriculture is an institution that is well known to farmers. A foundation sponsored jointly by private insurance companies and the farmers' association, under Swiss accident insurance law it acts as the agent of the Swiss Accident Insurance Commission (Schweizerische Unfallversicherungsanstalt) in the agricultural sector. 
data on manure facilities. We chose the eastern Swiss cantons of St Gall, Appenzell Innerrhoden, and Appenzell Ausserrhoden for the study as the agriculture found there is representative of Switzerland as a whole. From a total of 9987 livestock farms we selected a sample of 210 , or $2 \cdot 1 \%$. This sample size was chosen to fit in with our personnel resources and related practical considerations.

Politically, each canton is divided into districts, which in turn are made up of autonomous municipalities. We used these structures as the basis for sampling, which was carried out with a cluster sampling technique with several levels of stratification. This method allowed several levels of randomisation and gave each local unit (municipality or district) an equal chance of selection. The clusters consisted of the 18 districts located in the three cantons. With a random sampling procedure, one municipality was selected from each district of up to four municipalities, two from each district of five to eight municipalities and three from each district of nine or more municipalities.

Letters explaining the aims of the study and requesting a complete list of local farms were then sent to the selected municipalities under the letterhead of the Advisory Board for Accident Prevention in Agriculture. All of the municipalities provided lists. The lists were pooled and a random sample of 305 livestock raising farms was drawn, consisting of the desired sample of 210 farms plus a reserve to cover dropouts or refusals, and listed by municipality. The principal investigator wrote to the first 210 farms selected (the primary sample), asking the farmers to participate in the study. The letters were followed up by telephone calls, during which the study objectives were again explained and an interview appointment requested.

Data were gathered by personal interview (in some cases by telephone) with a standard questionnaire, and by inspection of manure systems. Part one of the questionnaire elicited detailed demographic data, including the number of farm personnel, the exact location of the farm, and the number and type of livestock. Part two elicited technical data on the liquid manure system, such as the number, age, and type of manure pits, pit covers (including those for manholes and other access points), emptying systems, conduits or piping and back flow prevention systems between livestock confinement areas and manure pits, and the type(s) of manure agitator used. Part three of the questionnaire contained questions on accidents related to manure that had occurred on the farmer's own farm. Part four was designed to gather data on the safety standard of the liquid manure system and the farmer's theoretical knowledge of liquid manure management. The results obtained with this last section of the questionnaire will not be presented here.

To increase the reliability of the responses, in the course of the interview informants were asked several different questions relating to possible exposure to liquid manure. All reported accidents were recorded on a separate form. As a further gauge of the reliability of the data, the interviewers recorded their impression of the informant's attitude at the beginning and again at the end of the visit, classing it as (a) uninterested or suspicious, $(b)$ indifferent, or $(c)$ well disposed or cooperative. Because part of the Advisory Board's activities involves cooperation with insurers, informants were given a written assurance that the completed questionnaires would remain with the doctors and that only anonymous data would be analysed and published.

The interviews were conducted in summer 1990 with the farmers themselves where possible, or if a farmer was unavailable, a designated deputy (usually the spouse). After the interview a joint inspection of the liquid manure system was carried out. Where the interview was conducted with a deputy, the sections of the questionnaire on theoretical knowledge and earlier accidents were completed during a subsequent telephone interview with the farmer. Of the 210 farms surveyed, 160 were visited by one of the doctors (SB, after thorough training by Advisory Service experts) as part of the work for his doctoral dissertation and 50 by one of the agricultural experts (GT).

For the purposes of the study an accident related to manure was defined as any accident with direct involvement of liquid manure, manure gases, or a manure pit or other manure storage facility. Accidents involving mobile tanks that related to the tanks' function as vehicles rather than as liquid manure containers were not included.

We distinguished between two categories of accident related to manure. (1) Major accidents, which involved human exposure and resulted in death or admission to hospital, or which became the subject of a police or newspaper report. This category was intended to cover the type of accident usually reported in specialist publications and the media. (2) Minor accidents, which included all accidents related to manure that ended without serious harm to humans or involved animal exposure only. We defined this category to obtain data on those accidents related to manure that generally escape wider attention. Accidents related to manure involving animals were included in the minor accident category, as they usually also expose humans to risk in one way or another. We chose the accident incidence as a quantitative measure of the risk to persons living or working on farms. It was calculated from the following formula:

$$
\text { Incidence of accidents }=\frac{\begin{array}{c}
\text { number of accidents } \\
\text { between } 1981 \text { and } 1990
\end{array}}{\begin{array}{c}
\text { exposure potential } \\
\text { (number of people) } \\
\times 10 \text { years }
\end{array}}
$$

The exposure potential was the total number of people living or working on the surveyed farms. This figure was determined for the years 1986 and 1990, and the mean of the two was used to calculate the incidence.

Our description of accident circumstances 
is based on all reported events, including those that occurred before the period used in calculating the incidence.

Data entry and analysis was carried out with File-Maker Pro running on an Apple Macintosh cx PC.

\section{Results}

GENERAL

Of the 210 farms originally contacted (the primary sample), 61 dropped out. Of these, 29 farmers declined to participate, 16 farms had been closed or lacked a liquid manure system, and 16 could not be contacted by telephone. The dropouts were replaced with farms from the reserve list. As foreseen, visits and interviews were conducted at a total of 210 farms.

The interviewers rated 174 informants $(83 \%)$ as well disposed or cooperative, 32 as indifferent, and four as uninterested or suspicious at the beginning of the interview. The interviewer changed the ratings of half the informants scored in the last two categories to well disposed or cooperative at the end of the visit. Thus, by the end of the visit, which (including inspection of the liquid manure system) generally lasted one to two hours, a total of 191 informants (91\%) were rated as well disposed or cooperative by the interviewers.

\section{DEMOGRAPHIC CHARACTERISTICS OF THE} SURVEYED FARMS

Table 1 compares the demographic features of the sample with the averages for Switzerland as a whole. At 664 and 666, respectively, the number of people living or working on the 210 farms in the sample remained almost constant from 1986 to 1990 . The number of full time farm workers was unchanged in this period. The sample included 71 farms of less than 10 hectares and only five of more than 30 hectares. Beef cattle were raised on 209 farms. On 56 farms an average of 61 pigs were raised for meat, and on 31 farms an average 8.7 pigs were raised for breeding purposes.

\section{LIQUID MANURE SYSTEMS}

The study design ensured that all farms in the sample produced and recycled liquid manure. In all, 569 manure pits were reported. As figure 1 shows, there was a wide range in the number of pits per farm, with the average at 2.7 . As well as modern facilities, we also encountered many old manure pits. Figure 2 gives a breakdown of the liquid manure storage capacity found on farms in the sample.

In general the older systems tended to present greater hazards, whereas the more mod-

Table 1 Characteristics of cattle and pig farms: comparison of the study sample and Switzerland as a whole

\begin{tabular}{lcc}
\hline & $\begin{array}{c}\text { Sample } \\
\text { average }\end{array}$ & $\begin{array}{l}\text { Swiss } \\
\text { average }\end{array}$ \\
\hline Farm area (hectares) & 13.8 & 13.6 \\
Height above sea level (m) & 684 & 703 \\
Large livestock/farm & 22.6 & 19.4 \\
Pigs (for meat)/farm & 23.0 & 22.9 \\
Pigs (breeders)/farm & 2.6 & 2.7 \\
\hline
\end{tabular}

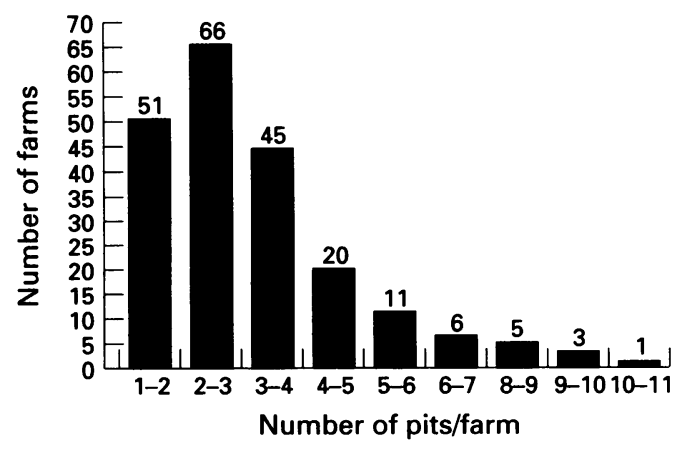

Figure 1 Number of manure pits/farm $(n=208)$.

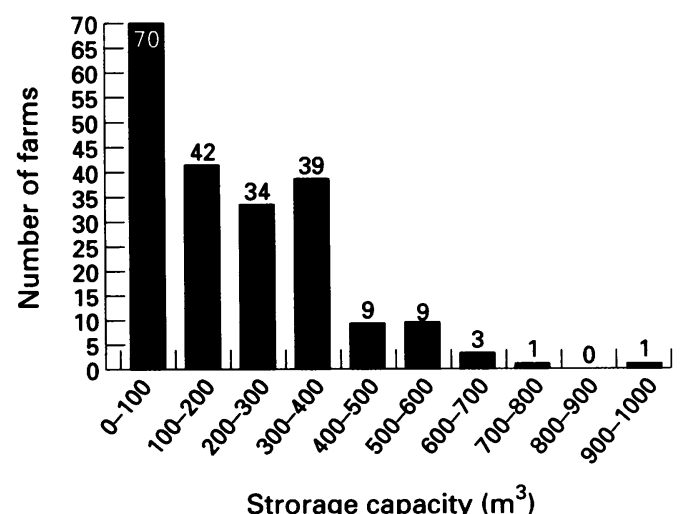

Figure 2 Total liquid manure storage capacity/farm $(n=208)$.

ern systems were safer. Of the older pits $68 \%$, and of the newer systems $58 \%$ used simple floor channels for the removal of waste from the animal enclosures. Of the newer systems $36 \%$ incorporated hydraulic manure removal systems with slide gates, compared with only $12 \%$ of the older systems. The proportion of storage pits under buildings was only $0.5 \%$ for newer systems, compared with $4 \%$ for older systems. The survey showed that $86 \%$ of the newer facilities were equipped with agitators, as opposed to only $60 \%$ of the older facilities. Of the newer systems $56 \%$ were equipped with built in (non-removable) agitators, compared with $12 \%$ of the older systems. In the sample $90 \%$ of the farms had pit covers that were assessed as safe. Fifty five per cent, including many farms with otherwise safe systems, had unsafe pit covers (cracks wider than $1 \mathrm{~mm}$ in the concrete cover, severe corrosion of the underside of the cover, exposed reinforcing, rotten boards). Pits with wooden covers of one sort or another (beams or boards) were seen at 62 farms (30\%). Eight farms had pits covered with broken or badly warped boards, and 13 had pits without covers. When badly defective manhole or maintenance covers were included (cover missing, bent, rotten, crumbling, or badly rusted), $75 \%$ of farms had pit covers that presented accident risks. Gas retention systems between pit and livestock enclosure were inspected but could not be tested. These were assessed as functional on 110 farms, while the remaining 100 had systems that were of doubtful efficacy or were unsafe. 
Table 2 Incidence of accidents related to manure

\begin{tabular}{lllllcc}
\hline & $\begin{array}{l}\text { Accidents } \\
n\end{array}$ & $\begin{array}{l}\text { Persons } \\
\text { injured } \\
n\end{array}$ & Period & $\begin{array}{l}\text { Exposure } \\
\text { potential } \\
n\end{array}$ & $\begin{array}{l}\text { Accidents/ } \\
1000 \\
\text { person-years }\end{array}$ & $(95 \%$ CI) \\
\hline Major accidents & 5 & 8 & $1981-1990$ & $665^{\star}$ & $0 \cdot 8$ & $(0 \cdot 2-1 \cdot 9)$ \\
Minor accidents (people) & 9 & 9 & $1981-1990$ & $665^{\star}$ & $1 \cdot 4$ & $(0 \cdot 5-2 \cdot 7)$ \\
Minor accidents (animals) & 55 & - & $1981-1990$ & $665^{\star}$ & $\begin{array}{r}8 \cdot 3 \\
10 \cdot 4\end{array}$ & $(7 \cdot 8-13 \cdot 3)$ \\
Total & - & - & & & \\
\hline
\end{tabular}

^Mean, $1986(664)+1990(666)$.

\section{ACCIDENT FREQUENCY}

The informants reported a total of 126 minor and seven major accidents from their own farms, the earliest of which had occurred in 1940. The incidences given in table 2 were calculated with data for the 10 year period 1981-90. We restricted ourselves to this period, as the incidence of minor accidents decreased the further back we went (fig 3). There are two possible explanations for this: (a) informants were better able to recall more recent than less recent events, or $(b)$ there has been a real increase in the frequency of accidents. We favour the first explanation, as we know of no factor that could account for such a massive increase in the frequency of minor accidents over the past few decades.

The only major accident with deaths on a farm in our sample occurred in 1956, when three adults died of gas poisoning. The few deaths and the difficulty of determining exposure time and exposure potential make it impossible to calculate a mortality.

\section{MAJOR ACCIDENTS}

Seven major accidents related to manure were reported from farms in our sample. Six of these involved poisoning by manure gases and the seventh was a major fire caused by ignition of methane. In six cases the manure had been agitated, whereas in the seventh no information on this point was available. Four of the accidents occurred in the manure pit. Three occurred in areas of buildings directly connected to the pit and were associated with failure of gas retention systems. Twelve people

Figure 3 Distribution of minor accidents related to manure, $1931-90(n=$ 124; two accidents could not be dated exactly).

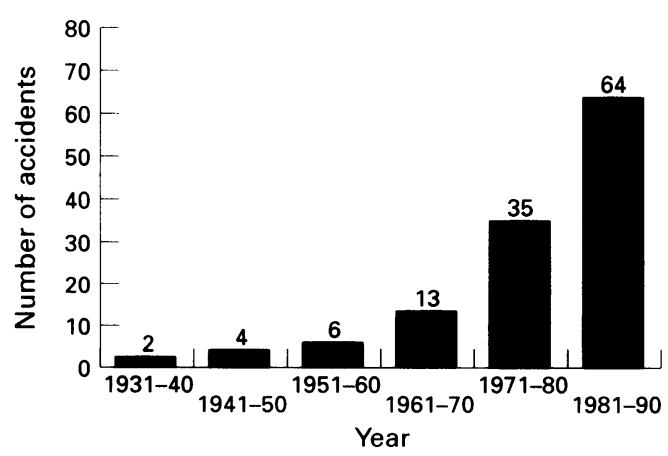

Table 3 Scenes of minor accidents related to manure

\begin{tabular}{lrl}
\hline & $n$ & $(\%)$ \\
\hline Manure pit & 104 & $(82 \cdot 5)$ \\
Livestock confinement area & 12 & $(9 \cdot 5)$ \\
Manure container & 3 & $(2 \cdot 4)$ \\
Manure channel & 3 & $(2 \cdot 4)$ \\
Other & 4 & $(3 \cdot 1)$ \\
Total & 126 & $(100)$ \\
\hline
\end{tabular}

were involved as victims, rescuers, or both. Of these, nine had gas poisoning, among them four children aged three to 12 years. As well as the three deaths referred to above, the outcomes included two cases of toxic pulmonary oedema and one case of suspected psychoorganic syndrome.

\section{MINOR ACCIDENTS}

Most of the accidents in this category involved falls into manure pits or other liquid manure containers. Thirty eight people were involved, including 17 children. By definition (see Methods), this category excluded human deaths. Also there were 134 cases of animal exposure, with 51 animals killed. For the most part these were livestock or other domestic animals, but accidents involving wild animals were also reported.

One hundred and three minor accidents involved falls into manure pits or containers. Ten children, three adults, and 91 animals were victims of this type of accident. In some cases the victims were able to climb out unassisted. In 60 cases the pit covers were inadequate or the pit openings defective. In 25 cases there were no pit covers at all.

There were 18 cases of poisoning by toxic manure gases, and in all of these the manure had been agitated or otherwise disturbed by pumping or filling operations. In 11 cases manure gases had entered the affected areas through waste removal pipes leading to the manure pit. Four cases involving defective gas retention devices were reported. Three accidents occurred during attempts to retrieve animals or objects that had fallen into manure pits. Four of the five methane accidents occurred after the manure had been agitated (information on this point was lacking in the fifth case). There were five fires, three of which were ignited by burning cigarettes or the like. Five people had mild to moderate burns.

Most accidents occurred in or immediately adjacent to manure pits (table 3 ). Eleven of the 12 accidents that occurred in livestock confinement buildings were due to gas poisoning, caused by entry of gases from the manure pit into the building. In all of these cases the manure had been agitated and gas retention devices were either missing or defective.

\section{Discussion}

Current awareness of accidents related to manure is dominated by events that meet the criteria for major accidents (as defined above) and result in one or more human deaths. Although relatively rare, this type is docu- 
mented in numerous publications. ${ }^{3-10}$ From previous contacts with farmers we knew that they often reported accidents related to manure that did not result in death or illness. We therefore undertook this study to document the entire range of such events, from the catastrophic to those that ended harmlessly. We defined two categories of accident: major accidents, resulting in human death or admission to hospital or reports in the public media; and minor accidents, including all those that did not meet the definition for major accidents, along with those involving only animal exposure.

Three anecdotal reports may serve to show some of the differences between major and minor accidents related to manure and also show how easily a minor accident can develop into a tragic event. One of us (AK) recently visited a farm where a major accident related to manure had occurred. A farm worker had been overcome by manure gases and was admitted to hospital unconscious. Toxic pulmonary oedema was diagnosed. After an inspection of the accident scene coffee and cake were served in the farmhouse kitchen. During the conversation the farmer reported that on one occasion his two year old son had leaned over a railing to look into a manure pit while the agitator was in operation. Within a minute he became unresponsive. The farmer removed the limp child from the pit opening, sat him on his lap and waited. Within a few minutes the boy was playing happily again. This incident, apparently a case of mild hydrogen sulphide intoxication, can be classed as a minor accident related to manure.

One of the authors (BS) was himself the victim of a minor accident related to manure at the age of 18 years, when he became dizzy while shovelling dung into a manure pit opening in the middle of a cow barn. He was able to flee to an adjacent enclosure, where he collapsed and lay unconscious for 10-20 minutes.

The final anecdotal report shows that even events that by our criteria qualify as minor accidents - and therefore go unreported and are often enough quickly forgotten-may easily have catastrophic outcomes, with the victims saved only by good fortune and quick action by rescuers. While spreading manure on the fields one day, one of our informants suddenly missed his five year old son. Looking through the uncovered opening into the manure pit he saw floating on the surface of the liquid, a wooden toy that the child used to pull along by a string. He leaned into the pit and felt along the string until he was able to grasp the submerged child's hand and pull him out. Thinking that he was dead, the grief stricken mother took the child and held him tightly in her arms, whereupon he vomited a large quantity of manure, took a deep breath and regained consciousness. His recovery was so rapid that the family doctor to whom he was immediately taken could find no abnormality. The child continued to develop normally.

These accounts show that the term "accident related to manure" covers a much wider range of events than is reflected by publications. It was thus one of the objectives of this field study to obtain quantitative data on the full range of accidents related to manure and detailed descriptions of the events.

The sample of farms on which this study is based reflects conditions found throughout Switzerland and elsewhere in central Europe. Most of the farms we visited are small family operations, devoted to food cultivation and livestock production, and most of the farm workers are family members. The recycling of liquid manure as fertiliser for fields has considerable economic and environmental advantages for farmers.

We found a wide variety of liquid manure systems on the farms surveyed. As a result of additions and modifications made over the years, about $75 \%$ of the farms had more than one manure pit, and about $25 \%$ had more than four. No less than 15 of the 569 manure pits documented in our sample dated from the last century. A considerable number of pits were no longer in use. In terms of preventive medicine this is important, given that every manure pit is a hazard, regardless of its safety standard or whether it is still in use.

On the basis of the incidences found in this study we calculated accident rates of one per 420 farms per year for major accidents and one per 33 farms per year for minor accidents. Transposing these figures to the whole of Switzerland, based on a population of 6670000 (1990 census) and 86000 livestock farms, frequencies of 204 major and 2606 minor accidents related to manure per year can be estimated, or one major accident for every 13 minor accidents. This is yet another indication that widely publicised major accidents are only part of a much wider picture.

We must therefore assume that many more incidents occur in association with liquid manure systems than appear in accident statistics or are reported in the literature on occupational medicine. It is apparent that major accidents, until now the focus of all attention, are only the tip of the iceberg. Most minor accidents (the submerged part of the iceberg) involve animal exposure only. If these are excluded, we obtain incidences for accidents involving humans of 0.75 major and 1.35 minor accidents per 1000 person-years. The relatively small difference between these figures may indicate that, once an accident situation with human involvement arises, it very often escalates to the "major" level. Our figures also show that, per 1000 people living or working on farms, two accidents involving one or more people occur each year. One third of those involved are children under the age of six years.

Our informants reported seven major accidents related to manure. One of these was a fire in a barn that started when manure gas was ignited by an electric spark. The other six involved manure gas intoxication, with a total of nine victims, four of them children under 12 years of age. Of the nine victims, three died.

One hundred and twenty six minor acci- 
dents related to manure were reported. These involved 38 people (none of whom were seriously harmed) and 134 animals, of which 51 died. Our informants reported many more accidents with animal exposure from neighbouring farms not included in the study sample. Exposure to toxic manure gases caused the death of 100 swine in one of these accidents and of 25 cattle in another.

Accidents involving animal exposure not only cause financial loss, they are also significant from a preventive medicine viewpoint. Farm workers are likely to be endangered as they attempt to rescue livestock ${ }^{3}$ or remove dead animals. Furthermore, if an accident related to manure involving livestock occurs, it is reasonable to assume that the manure handling facilities or associated work methods have shortcomings that also create hazards for humans. This is why we included accidents with animal victims in the minor accident category.

The questionnaire was designed to maximise the internal validity of informants' responses. It included nine different questions designed to elicit information on accidents related to manure. Among these were questions about workers experiencing nausea during liquid manure operations, animal exposure, broken pit covers, or any rescues that might have been necessary. Informants were also asked directly about accidents related to manure. The two interviewers, SB (160 farms) and GT (50 farms), recorded 102 and 122 accidents related to manure, respectively, per 100 farms visited. The reliability of the data is supported by the attitude ratings given by the interviewers, with $91 \%$ of the informants described as well disposed or cooperative by the end of the visit.

Even so, it is likely that the incidences we have calculated still underestimate the frequency of minor accidents related to manure. It was apparent that many farmers wanted to present their farms in a good light. Also, we had gained the impression from previous dealings with farmers that many will not speak openly about difficult issues unless they have had a certain time to get to know and trust their interviewer. It was plainly impossible for the interviewer to gain an informant's complete trust during a visit lasting only two hours. We must therefore assume that some informants will have been unwilling to discuss a potentially touchy subject that could reflect negatively on them or their farms. The anecdotal report of the incident with the uncon- scious boy (already discussed) is a case in point. It was only mentioned during a relaxed chat over coffee and cake, after the official part of the visit had been concluded.

In contrast to the internal validity, we were unable to test the external validity of the calculated incidences, as the published literature to which we had access contains no relevant figures for comparison.

Our data show that the manure pit is the most common site of minor accidents related to manure and that the most common mechanism is a fall into the pit, usually as a result of a defective or missing cover. We encountered very few pit emptying systems that conformed to published safety standards. The variety of pit covers we saw defies description. They ranged from loosely laid wooden poles to rotten boards and steel mesh grates. Safe covers and an emptying system that does not require the pit to be uncovered or the manhole opened are thus minimum requirements for every liquid manure system, along with the removal of pits that are no longer needed.

The incorporation of improved safety features into new and existing facilities and the development of safer operating practices depend on the availability of systematic data on the hazards and accident mechanisms associated with liquid manure systems. The results presented here are a first step towards providing basic information of this kind.

We thank Mr Peter Boyle for translating the text into English and making valuable editorial suggestions and Mrs Ruth Birrer for preparing the manuscript. We thank Professor F Gutzwiller, Director of the Institut für Sozial- und Präventivmedizin, University of Zurich, and his coworkers, Dr B Bisig and Dr A Tschopp, for advice in planning the study. This study was Tschopp, for advice in planning the study. This study was
made possible by a research grant from the Schweizerischer mationalfonds, no $32-30119.90$.

1 Andermatt P, Lanfranconi B, Molinaro R, Robert C, Ruppen L. In: Unfallstatistik der Arbeitnehmer in der Schweiz 1988-92. CH-Luzern: Schweizerische Unfallversicherungsanstalt (SUVA), 1994:37-62.

2 Purschwitz MA, Field WE. Scope and magnitude of injuries in the agricultural workplace. $A m \mathcal{F}$ Ind $M e d$ 1990;18:179-92.

3 Osbern LN, Crapo RO. Dung lung: a report of toxic exposure to liquid manure. Ann Intern Med 1981;95:312-4.

Deaths associated with liquid-manure systems-United States. MMWR CDC Surveill Summ 1981;30:151-8.

5 Morse DL, Woodbury MA, Rentmeester K, Farmer D. Death caused by fermenting manure. $¥ A M A$ 1981;245: 63-4.

6 Fatalities attributed to methane asphyxia in manure waste pits-Ohio, Michigan. 1989. MMWR CDC Surveill Summ 1989;38:583-6.

7 Hagley SR, South DL. Fatal inhalation of liquid manure gas. Med F Aust 1983;2:459-60.

8 Klein W. Über die Vergiftung durch Einatmen von Kloakengas. Dtsch $Z$ gericht $M e d$ 1922;1:228-41.

9 Death in a farm worker associated with toxic gases from a liquid manure system-Wisconsin. MMWR Surveill Summ 1978;27:47-8.

10 Aufdermaur F, Tönz 0 . Kindliche Jauchegasvergiftungen bei Benutzung "rustikaler" Aborte. Schweiz Med Wochenschr 1970;100;894-6. 